\title{
VALUE AS A SOCIOLOGICAL CONCEPT
}

\section{AMOS H. HAWLEY}

Kenan Professor of Sociology, Emeritus

University of North Carolina, Chapel Hill

Mid-American Review of Sociology, 1976, Vol. 1, No. 2:1-5

It appears to be a fact that every advanced civilization retains various survivals from its past, such as superstitious, magical practices and archaic ways of doing things. Perhaps it is because of some generic similarity between a civilization and an academic discipline that the latter also contains inconsistent and useless elements. Without some such explanation it is difficult indeed to understand how a discipline that is growing so self-conciously in methodological sophistication and theoretical incisiveness is able to preserve in its dictionary a concept as opaque as value. It is all things to all people: goals, objects, conditions, motives, attitudes, criteria of behavior, and so on. Nevertheless, the concept has not only survived, it has gained currency in recent years. This, too, defies rational explanation. It might be expressive of a spreading feeling of guilt over contra-humanistic tendencies in sociology; it could be due to a penchant for obfuscation among sociologists; or it might reflect a need for a waste-basket concept in which to pitch the loose ends of theoretical speculations. One guess is as good as another.

To lend some substance to my derogatory remarks about this most beatific of concepts I should like to refer to a widely cited paper by two anthropo-sociologists, Evon Z. Vogt and John M. Roberts, titled "A Study of Values." 1 The purpose of their study was to discover "how values function in organizing behavior." The study dealt with five culturally differentiated groups-Zuni, Navajo, Mormon, Spanish-American, and Texan homesteaders, all of whom occupy, or did at the time of investigation, a single geographic region, the Gallup region in New Mexico. Intensive field investigation revealed that the culturally differentiated groups are different in a number of respects, a finding the significance of which can be readily appreciated. Some, such as the Zuni, Navajo, and Mormon, ${ }^{2}$ engage in cooperative behavior, while the Texans practice self-reliance. The Mormons are enmeshed in a theocratic hierarchy. The Zuni, on the other hand, are organized in a "series of interlocking religious, kinship and secular units." "No true Zuni," the researchers discovered, "wishes to live away from Zuni, particularly in the wintertime." Theirs is an "avoidance of excess" way of life. The Spanish-Americans are 
traditionalists; their attitude to curiosity is expressed in "Quien sabe?" The conclusion from this review of group characteristics is that differences in culture can thus be related to differences in values." So striking in originality is the conclusion that one is impelled to reread the foregoing paragraphs to discover how it was reached. The effort is unrewarded, however, for no clue is given as to the nature of value or as to how it is distinguished from culture. Evidently the author has a unique capacity for insight, if not for elucidation.

The next kind of evidence marshalled by the authors concerns responses of the several groups to a crisis, namely, that represented in a severe drought. It is learned that the Zuni and Navajo intensify their ceremonial activity, the Spanish-Americans do nothing, the Mormons hold prayer meetings, and the Texans advocate seeding the clouds while sending off appeals to the Governor of the State for financial aid. These observations lead the authors to another ingenuous conclusion: "Each group responds differently to this problem (drought) in terms of its distinctive value orientation."

The Vogt-Roberts paper illustrates several of the more prominent characteristics of the sociologist's value. Of these are most conspicuous is that the denotative content of the concept can only be apprehended intuitively. Experts, such as authors of the study cited here, Talcott Parsons, Gideon Sjoberg, and many others, have only to gain a nodding acquaintance with a people or a society and, without being distracted by ordinary rules of inference, they know its values. They can prepare exhaustive lists of values in the countries they visit and, while still in full stride, they can advise their governments on how values should guide policy formation toward the respective foreign societies. William Kolb has drawn up a list of values developing countries do not have; ${ }^{3}$ Philip Hauser has an extensive list of values such countries do have; ${ }^{4}$ and Seymour M. Lipsit has detailed the values possessed in developed countries. There are other listings too numerous to mention. Value listing can be fun.

The reliance on intuition seems at first glance to be a scientific paradox. But then one learns from another source that there is a rational explanation for use of the "intuitive method." It seems that values are internalized; they disappear from view and no one knows where they go. The only way of retrieving them for purposes of observation is by means of the "intuitive method."

A further characteristic of values is that they are self-generative. Vogt and Roberts are able to dispense entirely with any concern for the his- torical circumstances that attended the behaviors of the several groups. Apparently there is nothing in the past of each group that might account for the values held. It must be admitted, of course, that since values are without definition, it would be difficult to connect them with any thing in particular. To be absolved of any responsibility for historic perspective is a genuine convenience. A short, added step brings one to the conclusion that the values of any one moment in time have no conection with the values of the next moment. Thus the "protestant ethic" sprung fullblown from no-where. Later it changed its shape and emerged in a distant place as the Buddhist ethic.

The great importance of values, their dubious parentage notwithstanding, is their ability to operate as efficient causes of behavior. Value is the sociologist's equivalent to the psychologist's motive; both concepts are equally immune to the ordinary canons of observability and verifiability. The student needs no special methods or procedures to establish the causal power in any instance. He merely needs to say that any given behavior is caused by a value or values and it is so. The great virtue of values in this respect is that causation is endogenous. When things cause themselves a lot of time is saved that might otherwise be spent in running around looking for logical connections, exogenous variables and other scientific gimmicks.

It is in keeping with the formlessness of values that they are nondimensional. Unlike the economist's value, the sociological value has no scalar unit. ${ }^{6}$ It is neither large nor small, strong nor weak, intensive nor unintensive. It simply is either present or absent. Thus all values are equal and comparable. But there is one exception. Values are infected with inertia which increases with time. They seem to gather weight. A thousand year old value is more inert than is a one hundred year old value.

The non-dimensionality of values suggests that they are the subjects of inassive consensus. This -is the impressiori that Vogt and Rolserts create, for they have nothing to say concerning any differentials that might exist. Occasionally one encounters references to value systems as though there might be some ordinal or hierarchial arrangement. But if the searcher after meaning expects any enlightenment on this score, he is bound to be disappointed. Michael Mann concluded from his study of data from numerous surveys reporting yes and no answers to value issues that there is no consensus in democratic societies. ${ }^{7}$ Critics might object that his data pertained not to values but to slogans, symbols, or 
other surrogates of values. The significance of the difference alluded to here is elusive.

One further attribute of the sociologists' value is palpable. That is its moral loading. There are only good values; bad values don't exist. Selfaggrandizement, loop-hole legality, serial polygyny, extermination of political dissidents, body-counts of enemy dead, religious opportunism, class approved prejudice, and many other similar forms of behavior, though widely approved and practiced, are not dignified as values. If the term is reserved for behaviors that are "good," what word are we to use for the bad things people do so frequently and with such obvious pleasure?

Philistine that I am, I recognize the ingeniousness of the value concept. It would be difficult to imagine a more thoroughly counterproductive idea. But if one clings to the old-fashioned notion that science presupposes verifiability in observation, he is or should be contented with behavior as his datum. Behavior is accessible to observation by an indefinite number of people. Even so, of course, it presents problems of recognition and classification that are serious enough. Nothing is to be gained by further complicating those problems. Nor is there any technique in the sociologist's methodological equipment that enables him to see behind behavior, to identify motive, intent, or what not. He may find it expedient to employ one kind of surrogate or another in different situations, but his substitute is only as good as it is verifiable. It is obvious to everyone that all behavior, even the most trivial, is evaluational; it is goal-seeking, preferential, conditional discriminatory. These properties can be extracted by inference and made the subject of conversation. To proceed from there to the endowment of any such property with an independent existence in what is ostensibly a scientific context is to defeat communication and the entire scientific enterprise.

My remarks in this diatribe are addressed only to value as a scientific concept. I have no quarrel with use of the term in humanistic discourse. There the object of enquiry and the rules of procedure are different. The sociulogist is well advised to leave the concept with the humanist and to confine his attention to more mundane things.

\section{NOTES}

1. Scientific American, 195 (1956): 25-30. An earlier report on this study appeared as Evon Z. Vogt and Thomas F. O'Dea, “A Comparative Study of the Role of Value in Social Action in Two Southwestern Communities," Amer. Sociol. Rev. 18 (1953): 645-654.

2. A fascinating discovery by the authors is that "the compact village settlement was a social invention of the Mormons." How, one wonders, was this invention dif- fused back through time to medieval Europe, the ancient civilized world, and to aboriginal peoples in all times and places?

3. "The Social Structure and Function of Cities," Economic Development and Cultural Change 3 (1954): 30-46.

4. "Cultural and Personal Obstacles to Economic Development in Less Developed Countries," Human Organization XVIII (1959): 82.

5. "The Value Patterns of Democracy," Amer. Sociol. Rev. 28 (1963): 515-531.

6. In a refreshing display of candor Harold Fallding declares that "we cannot work out any simple objective measures that conceive of human values (sicl) by analogy with the economic conceptions of value, ..." ("A Proposal for the Empirical Study of Values," Amer. Sociol. Rev. 30 [1965]: 224).

7. "The Social Cohesion of Liberal Democracy," Amer. Sociol. Rev. 35 (1970): 423-440. 